\title{
Management of Iron Deficiency Anaemia in Inflammatory Bowel Disease
}

\author{
Kristine Michelle Jimenez Christoph Gasche \\ Division of Gastroenterology and Hepatology, Department of Internal Medicine III, Medical University of Vienna, \\ Vienna, Austria
}

\section{Keywords}

Inflammatory bowel disease · Crohn's disease - Ulcerative colitis · Anaemia · Iron deficiency

\begin{abstract}
Inflammatory bowel disease (IBD) is a group of chronic relapsing inflammatory disorders affecting the large and small intestine, with a rising worldwide incidence and prevalence. Anaemia is the most common extraintestinal manifestation of IBD, correlating with disease activity, and tending to relapse even after successful therapy. Iron deficiency is the most common cause; however, it often manifests in combination with anaemia of inflammation. As such, multiple parameters are used for the diagnosis of iron deficiency anaemia in IBD. Timely recognition and selection of appropriate therapy leads to an improvement in the quality of life and prevention of potential sequelae. Oral iron can be effective under specific circumstances; however, as luminal iron changes microbiota and bacterial metabolism, oral administration should be avoided. Intravenous iron is preferred as it bypasses the sites of inflammation. Nevertheless, the optimization of IBD treatment should occur simultaneously, as this improves both patient condition and response to iron therapy. Herein, we discuss the screening, diagnosis, selection of therapy, and follow-up for iron deficiency anaemia in IBD.
\end{abstract}

(c) 2019 S. Karger AG, Basel

\section{KARGER}

() 2019 S. Karger AG, Basel

E-Mail karger@karger.com

www.karger.com/aha

\section{Introduction}

Inflammatory bowel disease (IBD) is a group of chronic relapsing inflammatory disorders affecting the large and small intestine, eventually leading to mucosal ulceration and bleeding. The exact aetiology is unclear; however, the pathogenesis is multifactorial, involving genetic susceptibility, immunity, environment, and intestinal microbiota. It has a rising worldwide incidence and prevalence, with the highest rates in westernized nations [1].

IBD is associated with multiple extraintestinal manifestations, involving the musculoskeletal, dermatologic, hepatopancreatobiliary, ocular, renal, and even pulmonary systems. However, the most common complication of IBD is anaemia. A recent systematic review by Filmann et al. [2] reported an overall prevalence of about $24 \%$ in IBD. Prevalence is higher in Crohn's disease as compared to ulcerative colitis, and over half of all anaemia cases in IBD are due to iron deficiency.

Multiple factors in IBD contribute to iron deficiency: intestinal blood loss, diminished dietary iron intake, as well as duodenal disease involvement or surgical removal of the duodenum causing diminished iron absorption. Iron stores are then depleted, leading to the development of iron deficiency anaemia (IDA).

However, chronic inflammation also leads to anaemia of inflammation (AI), the second most common cause of 
anaemia in IBD. Inflammatory cytokines increase the production of liver hepcidin, which blocks ferroportin-1 and prevents iron release from enterocytes, macrophages, and hepatocytes. Despite adequate iron stores, iron is sequestered from erythropoiesis and anaemia develops $[3,4]$.

Anaemia is linked to disease activity, as active disease exacerbates the factors that lead to IDA as well as AI. Often, the anaemia present in IBD is mixed, with features of both IDA and AI [5].

\section{Diagnosis of IDA in IBD}

The European Crohn's and Colitis Organization (ECCO) recommends anaemia screening for patients in remission or mild disease every 6 to 12 months. For outpatients with active disease, screening should be every 3 months [5]. Screening should include a complete blood count, serum ferritin, and C-reactive protein (CRP). In addition, serum vitamin $B_{12}$ and folic acid should be measured at least once a year for patients at risk for these deficiencies (small bowel disease or resection) and more frequently in patients with extensive small bowel resection, ileal pouch surgery, or extensive ileal involvement.

Anaemia diagnosis in IBD follows the recommendations of the World Health Organization (WHO): in adult males, this is a haemoglobin $(\mathrm{Hb})$ of $<13.0 \mathrm{~g} / \mathrm{dL},<12.0 \mathrm{~g} /$ $\mathrm{dL}$ in adult nonpregnant women, and $<11.0 \mathrm{~g} / \mathrm{dL}$ in pregnant women [6]. However, multiple factors such as age, ethnicity, smoking habit, or altitude can alter these thresholds $[7,8]$.

In addition to the aforementioned screening parameters, the basic workup for diagnosed anaemia should include reticulocyte count, serum ferritin, and transferrin saturation (TfS) [5]. There is currently no standard clinical test which can clearly distinguish iron deficiency when inflammation is present [3], and often a combination of parameters may be necessary for the management of IDA in IBD. While bone marrow smears may directly diagnose IDA, this method is invasive and is only considered when other parameters are in conflict and therapy remains ineffective. In over 25 years of clinical practice, however, we have never had to resort to this.

IDA is typically characterized as microcytic and hypochromic anaemia; however, early IDA can appear normocytic. The presence of concomitant normocytic (AI) or macrocytic (vitamin $B_{12}$ deficiency, folate deficiency, thiopurine therapy) anaemia can mask the presence of IDA. For a mixed aetiology, a high red cell distribution width can help identify the presence of concomitant iron deficiency [9]. Thalassemia can also present as microcytic hypochromic anaemia and should be considered in endemic populations. Reticulocyte counts can be low to normal, depending on how impaired erythropoiesis is due to iron deficiency. Reticulocyte $\mathrm{Hb}$ content reflects the availability of iron for erythropoiesis and is reduced in IDA and IDA with AI. It is, however, not widely available [3]. Platelet and leukocyte counts help rule out pancytopenia [5].

Ferritin is low in IDA but may increase during inflammation. A serum ferritin of $<30 \mu \mathrm{g} / \mathrm{L}$ is generally indicative of IDA. However, if inflammation is present (elevated CRP, erythrocyte sedimentation rate, or leukocyte counts; diarrhoea; haematochezia; or endoscopic inflammation), the limit is raised to $100 \mu \mathrm{g} / \mathrm{L}$. The cut-off for TfS is set at $<16 \%$ for iron deficiency. However, AI may also present with a low TfS $[3,5]$. The presence of inflammation can also be detected using inflammatory cytokines such as interleukin-6. Hepcidin is decreased in response to iron deficiency; however, it is increased in response to inflammation.

Soluble transferrin receptor (sTfR) is another parameter that increases during iron deficiency. While the concentration of sTfR is mostly unaffected by inflammation, there is no consensus on the appropriate limits and no standard test. If available, an elevated sTfR or sTfR/log ferritin index $>2$ points to concomitant IDA [3]. A summary of diagnostic parameters can be found in Table 1 .

\section{Treatment of IDA in IBD}

Once IDA has been diagnosed, prompt and appropriate therapy is imperative. Quality of life greatly improves with correction of anaemia [10-12]. Furthermore, iron is also vital for many cellular processes beyond oxygen transport, and iron deficiency can be symptomatic even without manifest anaemia [13-16].

The goal of iron therapy is complete normalization of $\mathrm{Hb}$ and restoration of iron stores. The duration until this is achieved can vary, depending on the severity of anaemia. However, $\mathrm{Hb}$ should increase by at least $2 \mathrm{~g} / \mathrm{dL}$ within 4 weeks of treatment $[5,17]$. Appropriate IBD management should be undertaken simultaneously, to prevent further iron losses and alleviate concomitant AI. A simplified management scheme can be found in Figure 1.

\section{Oral Iron}

In our view, it is best to avoid oral iron therapy in IBD to relieve the intestinal site of inflammation from poten- 


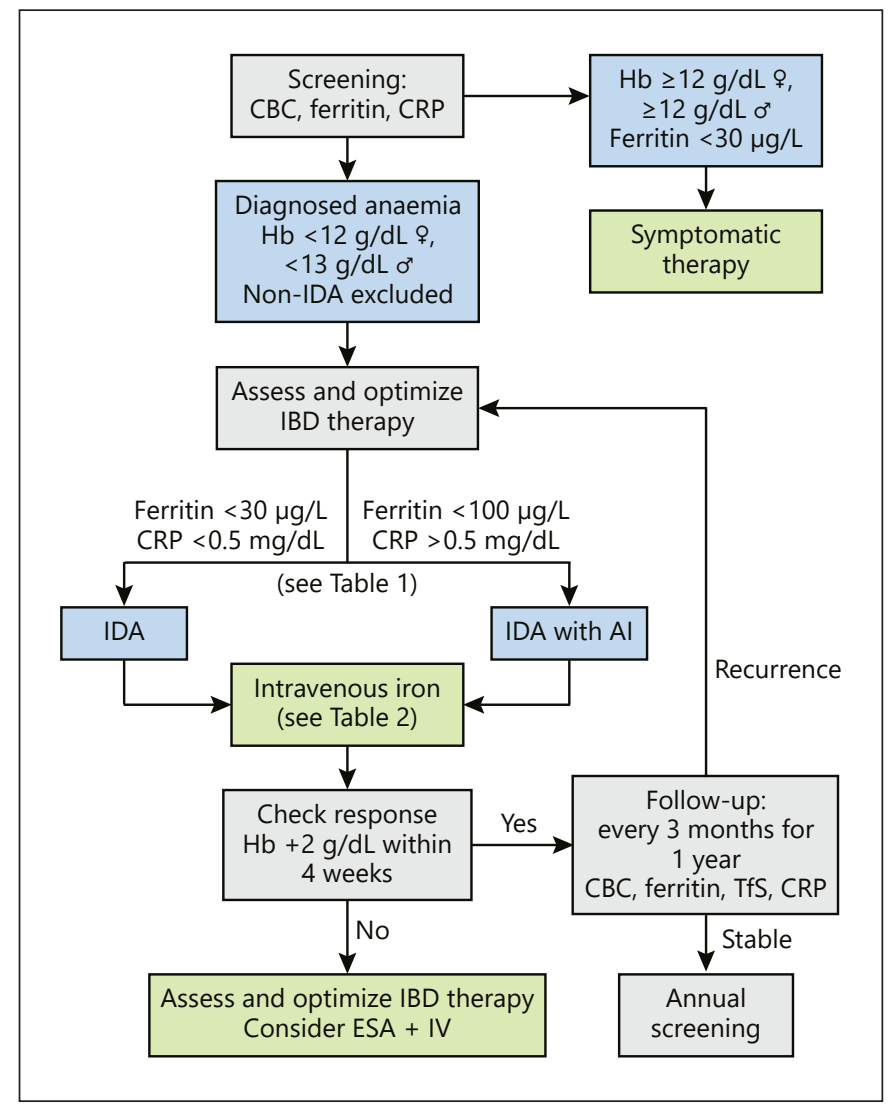

Fig. 1. Simplified management scheme for iron deficiency anaemia (IDA) in patients with inflammatory bowel disease (IBD). AI, anaemia of inflammation; CBC, complete blood count; CRP, Creactive protein; ESA, erythropoiesis-stimulating agents; $\mathrm{Hb}$, haemoglobin; IV, intravenous; TfS, transferrin saturation.

tial harm and reduce the risk of triggering a flare. Oral iron alters the microbiota profile and metabolism, which likely influences the underlying intestinal disease [18, 19]. In animal models of colitis, oral iron exacerbates colitis and promotes carcinogenesis $[20,21]$. Furthermore, inflammation greatly diminishes the efficacy of oral iron. Duodenal disease involvement directly impairs iron absorption, and elevated circulating hepcidin blocks the release of iron taken up by enterocytes into circulation. Gastrointestinal side effects (abdominal pain, nausea, diarrhoea) further limit tolerability [22, 23].

If oral iron must be used, it should be limited to IBD patients with mild anaemia $(\mathrm{Hb} \geq 11.0 \mathrm{~g} / \mathrm{dL})$, with no active disease and no prior intolerance to oral iron [5]. The ECCO recommends a dose no higher than $100 \mathrm{mg}$ elemental iron per day [5]. However, lower doses (15-30 $\mathrm{mg}$ ) have been effective in other patient populations [24,
Table 1. Distinguishing iron deficiency anaemia (IDA), anaemia of inflammation (AI), and combined anaemia (AI + IDA)

\begin{tabular}{llll}
\hline Parameters & IDA & AI & AI + IDA \\
\hline Red cell indices & & & \\
MCV/MCHC & $\downarrow$ & $\downarrow$ to $\leftrightarrow$ & $\downarrow$ to $\leftrightarrow$ \\
Reticulocyte count & $\downarrow$ & $\downarrow$ & $\downarrow$ \\
RDW & $\uparrow$ & $\leftrightarrow$ to $\uparrow$ & $\leftrightarrow$ to $\uparrow$ \\
\hline Iron indices & & & \\
Ferritin, $\mu$ g/L & $<30$ & $>100$ & $30-100$ \\
Transferrin & $\uparrow$ & $\downarrow$ to $\leftrightarrow$ & $\leftrightarrow$ to $\uparrow$ \\
TfS & $<16 \%$ & $<20 \%$ & $<16-20 \%$ \\
sTfR & $\uparrow$ & $\leftrightarrow$ & $\leftrightarrow$ to $\uparrow$ \\
sTfR/log ferritin & $>2$ & $<1$ & $1-2$ \\
Hepcidin & $\downarrow$ & $\uparrow$ & $\downarrow$ to $\leftrightarrow$ \\
\hline Inflammatory parameters & & & \\
CRP & $\leftrightarrow$ & $\leftrightarrow$ to $\uparrow$ & $\leftrightarrow$ to $\uparrow$ \\
Interleukin-6 & $\leftrightarrow$ & $\uparrow$ & $\uparrow$ \\
ESR, leukocyte counts, clinical & & & \\
\multicolumn{1}{r}{ symptoms } & $\leftrightarrow$ & $\uparrow$ & $\uparrow$ \\
\hline
\end{tabular}

CRP, C-reactive protein; ESR, erythrocyte sedimentation rate; MCHC, mean corpuscular haemoglobin concentration; MCV, mean corpuscular volume; RDW, red cell distribution width; sTfR, soluble transferrin receptor; TfS, transferrin saturation.

25]. Studies in iron-deficient women show that frequent daily dosing reduces iron absorption and that alternateday single doses are more effective [26, 27]. There are also newer formulations of oral iron with ferric iron, such as ferric maltol, that were effective in patients with IBD who could not tolerate the standard ferrous formulations [28]. $\mathrm{Hb}$ should increase by at least $2 \mathrm{~g} / \mathrm{dL}$ within 4 weeks of treatment to be considered effective. If this is not the case, a shift to intravenous iron may be necessary.

\section{Intravenous Iron}

In IBD patients with moderate to severe anaemia, or with active disease, or where oral iron is not tolerated or ineffective, intravenous (IV) iron is the therapy of choice [5]. IV iron bypasses the inflammation-induced blockade of intestinal iron absorption and allows for faster iron repletion. A meta-analysis on studies comparing IV iron and oral iron in IBD found that IV iron was more effective at raising $\mathrm{Hb}$ and had a lower rate of treatment discontinuation due to adverse events or intolerance [29]. The main disadvantage is the higher cost of medication and the necessity for administration by a health professional. However, a study by Stein et al. [30] based in Germany found that patient outcome was better with IV iron, with 
Table 2. Simple scheme for estimation of iron need

\begin{tabular}{llrl}
\hline $\begin{array}{l}\text { Severity of iron } \\
\text { deficiency }\end{array}$ & $\mathrm{Hb}, \mathrm{g} / \mathrm{dL}$ & $\mathrm{BW}<70 \mathrm{~kg}$ & $\mathrm{BW} \geq 70 \mathrm{~kg}$ \\
\hline No anaemia & Normal & $500 \mathrm{mg}$ & $1,000 \mathrm{mg}$ \\
$\begin{array}{l}\text { Mild to moderate } \\
\quad \text { anaemia }\end{array}$ & $10-12$ (women) & $1,000 \mathrm{mg}$ & $1,500 \mathrm{mg}$ \\
$\begin{array}{l}\text { Severe anaemia } \\
\text { Critical anaemia }\end{array}$ & $7-10$ & $1,500 \mathrm{mg}$ & $2,000 \mathrm{mg}$ \\
\hline
\end{tabular}

BW, body weight; $\mathrm{Hb}$, haemoglobin.

fewer hospitalizations and an overall lower total health care cost as compared to oral iron. The immediate costs of IV iron may thus be offset by the long-term costs of ineffective oral iron therapy.

In the past, severe reactions were reported in response to high-molecular weight iron dextran. These reactions are rare with formulations in current use; a retrospective study in the US found 0.24 anaphylactic reactions per 1,000 infusions in IBD [31]. Death and other severe longterm sequelae are very rare, at about one for every five million doses [32].

Calculation of the appropriate dose was classically performed using the Ganzoni formula [33]. However, this formula is impractical and can underestimate iron requirements [34, 35]. A simple dosing scheme proposed by our group is recommended by the ECCO, as it had better efficacy and compliance compared to Ganzoni-based dosing (Table 2) [5, 10].

IV iron formulations are available in low- or high-molecular weight formulations (Table 3). The advantage of the high-molecular weight formulations is that larger doses can be administered in one session, whereas lowmolecular weight formulations would require more sessions and increase associated administration cost.

While the risk for a severe reaction to IV iron is low, it should only be administered by trained staff at a facility equipped for resuscitation. The European Medicines Agency no longer requires a test dose and instead recommends close monitoring for at least $30 \mathrm{~min}$ following infusion for all IV iron formulations [36].

$\mathrm{Hb}$ should increase by $2 \mathrm{~g} / \mathrm{dL}$ within 4 weeks of iron replacement. Ferritin is highly elevated in the first couple of weeks after iron infusion and is only reliable 8 to 12 weeks after the end of treatment. A TfS $>50 \%$ is indicative of iron overload and treatment regimen should be modified accordingly [37]. Depending on the initial severity and underlying cause, $\mathrm{Hb}$ correction may take up to 3
Table 3. Intravenous iron preparations

\begin{tabular}{|c|c|}
\hline Formulation & Dose per session \\
\hline \multicolumn{2}{|l|}{ Low dose } \\
\hline Iron gluconate & $\begin{array}{l}62.5-125 \mathrm{mg} / 100 \mathrm{~mL} 0.9 \% \mathrm{NaCl} \text { for } 20 \\
\text { min to } 1 \mathrm{~h}\end{array}$ \\
\hline Iron sucrose & $\begin{array}{l}100-200 \mathrm{mg} / 100 \mathrm{~mL} 0.9 \% \mathrm{NaCl} \text { over } 30 \\
\text { min minimum }\end{array}$ \\
\hline \multicolumn{2}{|l|}{ High dose } \\
\hline Ferric carboxymaltose & $\begin{array}{l}500 \mathrm{mg} / 100 \mathrm{~mL} 0.9 \% \mathrm{NaCl} \\
1,000 \mathrm{mg} / 250 \mathrm{~mL} 0.9 \% \mathrm{NaCl} \\
\text { Administered over } 15 \mathrm{~min}\end{array}$ \\
\hline Iron dextran & $1,000 \mathrm{mg} / 500 \mathrm{~mL} 0.9 \% \mathrm{NaCl}$ over $4-6 \mathrm{~h}$ \\
\hline Iron isomaltoside 1000 & $\begin{array}{l}500 \mathrm{mg} / 250 \mathrm{~mL} 0.9 \% \mathrm{NaCl} \text { over } 30 \mathrm{~min} \\
1,000 \mathrm{mg} / 500 \mathrm{~mL} 0.9 \% \mathrm{NaCl} \text { over } 1 \mathrm{~h}\end{array}$ \\
\hline Ferumoxytol & $\begin{array}{l}510 \mathrm{mg} \text { IV at } 30 \mathrm{mg} / \mathrm{s} \text { or infusion over } \\
15 \mathrm{~min}\end{array}$ \\
\hline
\end{tabular}

months and even longer to replace iron stores. Patients with posttreatment ferritin levels $<100 \mu \mathrm{g} / \mathrm{L}$ are more likely to recur within the first 4 months, $100-400 \mu \mathrm{g} / \mathrm{L}$ within the next year, and $>400 \mu \mathrm{g} / \mathrm{L}$ after 2 years [38]. Thus, it could be beneficial to aim for a higher ferritin level for iron therapy when using IV iron [5].

Patients not responding to IV iron may have concomitant AI and may be considered for treatment with erythropoiesis-stimulating agents (ESA). However, optimization of IBD should precede ESA use as appropriate therapy can improve response to IV iron. Furthermore, other potential causes of anaemia should be re-evaluated. If ESA are necessary, they should only be used in combination with IV iron and only to a maximum of $12 \mathrm{~g} / \mathrm{dL} \mathrm{Hb}$ [5].

Blood transfusions should only be used in patients who are critically anaemic $(\leq 7 \mathrm{~g} / \mathrm{dL} \mathrm{Hb})$ and haemodynamically unstable or have concomitant coronary heart disease or chronic pulmonary disease $[5,39]$. Transfusions are a temporary solution, and iron replacement is still needed to replete iron stores.

\section{Follow-Up}

Anaemia can recur within the first 10 months after completion of treatment, even if iron was administered intravenously $[38,40]$. Thus, patients should be monitored every 3 months in the first year after treatment, and every 6 to 12 months in the years thereafter. Parameters to be monitored include $\mathrm{Hb}$, ferritin, TfS, and CRP [5]. If $\mathrm{Hb}$ drops below the limits for anaemia, or serum ferritin drops below $100 \mu \mathrm{g} / \mathrm{L}$, treatment should be re-initiated 
[5]. Persistent IDA or rapid recurrence of IDA despite appropriate therapy could be a sign of ongoing disease activity, which should be appropriately managed. In premenopausal women with IBD, menstrual blood loss should also be considered.

\section{Iron Deficiency without Anaemia}

While there is a consensus for prompt treatment of IDA in IBD, there are no definitive recommendations for the treatment of iron deficiency without manifest anaemia (IDWA). In IDWA, iron stores are reduced as indicated by a ferritin $<30 \mu \mathrm{g} / \mathrm{L}$, or $30-100 \mu \mathrm{g} / \mathrm{L}$ if inflammation is present. Likewise, TfS may be $<16 \%$. Red cell indices may be altered: red cell distribution width increased, reticulocyte counts decreased, and $\mathrm{MCH}$ at the lower limit of normal. However, $\mathrm{Hb}$ remains within normal limits.

Despite $\mathrm{Hb}$ being within normal limits, patients with IDWA can suffer from a reduced quality of life [16]. Symptoms such as chronic fatigue, restless legs syndrome, or impaired cognitive function can improve upon iron therapy [13-15].

In one retrospective study on IBD patients with IDWA, only a fourth of patients recovered within the following year. Recovery was more common in patients who were male or had a ferritin of 30-100 $\mu \mathrm{g} / \mathrm{L}$. The remainder continued to have IDWA or progressed fully into anaemia [41]. Thus, these patients should also be monitored closely for developing anaemia or symptoms that may impact quality of life such as fatigue [16]. The decision to treat IDWA should be decided on a patient-to-patient basis. For IV iron, a single dose of iron as recommended in Table 2 may be used [5].

\section{Iron Deficiency, an Accomplice in Other IBD Sequelae?}

Iron is a vital element involved in gas exchange, mitochondrial function, DNA repair, free radical production in immunity, and a host of other cellular functions [4]. Chronic IDA also means chronic hypoxia, which in combination could elicit a maladaptive response in the context of chronic inflammation.

Iron deficiency is known to be associated with thrombocytosis, which is perhaps an evolutionary response to compensate for blood loss [42]. Thrombocytosis is also a feature of IBD, occurring in response to inflammation. However, iron therapy in patients with IBD reduces platelet number as well as platelet activity, indicating that iron deficiency itself is a contributor [43].
In cancer patients, where thrombotic events are a significant cause of morbidity and mortality, high platelet counts are a risk factor for venous thromboembolism [44]. Likewise, IBD patients are at considerable risk for thrombotic events, and risk increases when disease activity is highest [45]. Anaemia also correlates with disease activity, so both IDA and inflammation may be playing contributory roles in the pathogenesis of thrombotic events in IBD.

In our research, we have discovered that IDA alone can increase both arterial [46] and venous thrombotic tendency in animal models. Animal models of IBD are more susceptible to thrombosis, and haematologic examination of these models also show significant anaemia $[47,48]$. The increased thrombotic tendency in IBD may be the combined effect of both inflammation and iron deficiency.

Intestinal hypoxia is a feature of chronic inflammation. Oxygen consumption increases due to increased metabolic activity and immune cell activity, while intestinal perfusion is decreased. An adequate response to these changes promotes a return to normal intestinal homoeostasis [49]. Central to the regulation of this process is hypoxia-inducible factor- $2 a$, which we have found to also be involved in IDA-associated thrombocytosis [50]. IDA in IBD could thus contribute not only to increased thrombotic tendency, but also to dysregulation of intestinal homoeostasis.

\section{Conclusion}

Anaemia is the most common extraintestinal manifestation of IBD, and its major cause is iron deficiency. While appropriate disease management will prevent further iron loss, appropriate iron replacement therapy is needed to restore normal function. Careful monitoring for recurrence is necessary. The benefits of iron therapy may extend beyond reversal of anaemia, potentially influencing thrombotic tendency as well as the course of the disease itself.

\section{Disclosure Statement}

K.M.J. has no conflicts of interest to declare. C.G. has received research support and lecturing or consulting honoraria from AOP Orphan Pharmaceuticals, Biogena Naturstoffe GmbH, Insightra Inc., Shire Inc., and Vifor Int.

\section{Funding Sources}

Funding for research was supported by the Austrian Science Fund (P 27681).
Jimenez/Gasche 


\section{References}

1 Ng SC, Shi HY, Hamidi N, Underwood FE, Tang W, Benchimol EI, et al. Worldwide incidence and prevalence of inflammatory bowel disease in the 21st century: a systematic review of population-based studies. Lancet. 2018 Dec;390(10114):2769-78.

2 Filmann N, Rey J, Schneeweiss S, Ardizzone S, Bager P, Bergamaschi G, et al. Prevalence of anemia in inflammatory bowel diseases in european countries: a systematic review and individual patient data meta-analysis. Inflamm Bowel Dis. 2014 May;20(5):936-45.

3 Weiss G. Anemia of chronic disorders: new diagnostic tools and new treatment strategies. Semin Hematol. 2015 Oct;52(4):313-20.

4 Evstatiev R, Gasche C. Iron sensing and signalling. Gut. 2012 Jun;61(6):933-52

5 Dignass AU, Gasche C, Bettenworth D, Birgegard G, Danese S, Gisbert JP, et al.; European Crohn's and Colitis Organisation [ECCO]. European consensus on the diagnosis and management of iron deficiency and anaemia in inflammatory bowel diseases. J Crohns Colitis. 2015 Mar;9(3):211-22

6 World Health Organization, Centers for Disease Control and Prevention. Assessing the iron status of populations. 2nd ed. Geneva, Switzerland; 2007.

7 Beutler E, Waalen J. The definition of anemia: what is the lower limit of normal of the blood hemoglobin concentration? Blood. 2006 Mar; 107(5):1747-50.

8 Cook JD, Boy E, Flowers C, Daroca MC. The influence of high-altitude living on body iron. Blood. 2005 Aug;106(4):1441-6.

9 Oustamanolakis P, Koutroubakis IE, Messaritakis I, Kefalogiannis G, Niniraki M, Kouroumalis EA. Measurement of reticulocyte and red blood cell indices in the evaluation of anemia in inflammatory bowel disease. J Crohns Colitis. 2011 Aug;5(4):295-300.

10 Evstatiev R, Marteau P, Iqbal T, Khalif IL, Stein J, Bokemeyer B, Chopey IV, Gutzwiller FS, Riopel L, Gasche C; FERGI Study Group. FERGIcor, a randomized controlled trial on ferric carboxymaltose for iron deficiency anemia in inflammatory bowel disease. Gastroenterology. 2011 Sep;141(3):846-853.e1-2.

11 Gisbert JP, Bermejo F, Pajares R, Pérez-Calle JL, Rodríguez M, Algaba A, et al. Oral and intravenous iron treatment in inflammatory bowel disease: hematological response and quality of life improvement. Inflamm Bowel Dis. 2009 Oct;15(10):1485-91.

12 Wells CW, Lewis S, Barton JR, Corbett S. Effects of changes in hemoglobin level on quality of life and cognitive function in inflammatory bowel disease patients. Inflamm Bowel Dis. 2006 Feb;12(2):123-30.

13 Bruner AB, Joffe A, Duggan AK, Casella JF, Brandt J. Randomised study of cognitive effects of iron supplementation in non-anaemic iron-deficient adolescent girls. Lancet. 1996 Oct;348(9033):992-6.
14 Wang J, O’Reilly B, Venkataraman R, Mysliwiec V, Mysliwiec A. Efficacy of oral iron in patients with restless legs syndrome and a low-normal ferritin: A randomized, doubleblind, placebo-controlled study. Sleep Med. 2009 Oct;10(9):973-5.

15 Krayenbuehl PA, Battegay E, Breymann C, Furrer J, Schulthess G. Intravenous iron for the treatment of fatigue in nonanemic, premenopausal women with low serum ferritin concentration. Blood. 2011 Sep;118(12): 3222-7.

16 González Alayón C, Pedrajas Crespo C, Marín Pedrosa S, Benítez JM, Iglesias Flores E, Salgueiro Rodríguez I, et al. Prevalence of iron deficiency without anaemia in inflammatory bowel disease and impact on healthrelated quality of life. Gastroenterol Hepatol. 2018 Jan;41(1):22-9.

17 Gasche C, Waldhoer T, Feichtenschlager T, Male C, Mayer A, Mittermaier C, et al.; Austrian Inflammatory Bowel Diseases Study Group. Prediction of response to iron sucrose in inflammatory bowel disease-associated anemia. Am J Gastroenterol. 2001 Aug;96(8): 2382-7.

18 Lee T, Clavel T, Smirnov K, Schmidt A, Lagkouvardos I, Walker A, et al. Oral versus intravenous iron replacement therapy distinctly alters the gut microbiota and metabolome in patients with IBD. Gut. 2017 May;66(5):86371.

19 Zimmermann MB, Chassard C, Rohner F, N'goran EK, Nindjin C, Dostal A, et al. The effects of iron fortification on the gut microbiota in African children: a randomized controlled trial in Cote d'Ivoire. Am J Clin Nutr. 2010 Dec;92(6):1406-15.

20 Mahalhal A, Williams JM, Johnson S, Ellaby N, Duckworth CA, Burkitt MD, et al. Oral iron exacerbates colitis and influences the intestinal microbiome. PLoS One. 2018 Oct; 13(10):e0202460

21 Seril DN, Liao J, Ho KL, Warsi A, Yang CS, Yang GY. Dietary iron supplementation enhances DSS-induced colitis and associated colorectal carcinoma development in mice. Dig Dis Sci. 2002 Jun;47(6):1266-78.

22 Cancelo-Hidalgo MJ, Castelo-Branco C, Palacios S, Haya-Palazuelos J, Ciria-Recasens M, Manasanch J, et al. Tolerability of different oral iron supplements: a systematic review. Curr Med Res Opin. 2013 Apr;29(4):291-303.

23 Tolkien Z, Stecher L, Mander AP, Pereira DI, Powell JJ. Ferrous sulfate supplementation causes significant gastrointestinal side-effects in adults: a systematic review and meta-analysis. PLoS One. 2015 Feb;10(2):e0117383.

24 Makrides M, Crowther CA, Gibson RA, Gibson RS, Skeaff CM. Efficacy and tolerability of low-dose iron supplements during pregnancy: a randomized controlled trial. Am J Clin Nutr. 2003 Jul;78(1):145-53.
25 Rimon E, Kagansky N, Kagansky M, Mechnick L, Mashiah T, Namir M, et al. Are we giving too much iron? Low-dose iron therapy is effective in octogenarians. Am J Med. 2005 Oct;118(10):1142-7.

26 Moretti D, Goede JS, Zeder C, Jiskra M, Chatzinakou V, Tjalsma $\mathrm{H}$, et al. Oral iron supplements increase hepcidin and decrease iron absorption from daily or twice-daily doses in iron-depleted young women. Blood. 2015 Oct;126(17):1981-9.

27 Stoffel NU, Cercamondi CI, Brittenham G, Zeder C, Geurts-Moespot AJ, Swinkels DW, et al. Iron absorption from oral iron supplements given on consecutive versus alternate days and as single morning doses versus twice-daily split dosing in iron-depleted women: two open-label, randomised controlled trials. Lancet Haematol. 2017 Nov; 4(11):e524-33.

28 Gasche C, Ahmad T, Tulassay Z, Baumgart DC, Bokemeyer B, Büning C, et al.; AEGIS Study Group. Ferric maltol is effective in correcting iron deficiency anemia in patients with inflammatory bowel disease: results from a phase-3 clinical trial program. Inflamm Bowel Dis. 2015 Mar;21(3):579-88.

29 Bonovas S, Fiorino G, Allocca M, Lytras T, Tsantes A, Peyrin-Biroulet L, et al. Intravenous versus oral iron for the treatment of anemia in inflammatory bowel disease: A systematic review and meta-analysis of randomized controlled trials. Medicine (Baltimore). 2016 Jan;95(2):e2308.

30 Stein J, Haas JS, Ong SH, Borchert K, Hardt T, Lechat E, et al. Oral versus intravenous iron therapy in patients with inflammatory bowel disease and iron deficiency with and without anemia in Germany - a real-world evidence analysis. Clinicoecon Outcomes Res. 2018 Feb;10:93-103.

31 Akhuemonkhan E, Parian A, Carson KA, Hutfless S. Adverse reactions after intravenous iron infusion among inflammatory bowel disease patients in the united states, 2010-2014. Inflamm Bowel Dis. 2018 Jul; 24(8):1801-7.

32 Rampton D, Folkersen J, Fishbane S, Hedenus M, Howaldt S, Locatelli F, et al. Hypersensitivity reactions to intravenous iron: guidance for risk minimization and management. Haematologica. 2014 Nov;99(11):1671-6.

33 Ganzoni AM. [Intravenous iron-dextran therapeutic and experimental possibilities]. Schweiz Med Wochenschr. 1970 Feb;100(7): 301-3.

34 Kulnigg S, Stoinov S, Simanenkov V, Dudar LV, Karnafel W, Garcia LC, et al. A novel intravenous iron formulation for treatment of anemia in inflammatory bowel disease: the ferric carboxymaltose (FERINJECT) randomized controlled trial. Am J Gastroenterol. 2008 May;103(5):1182-92. 
35 Reinisch W, Staun M, Tandon RK, Altorjay I, Thillainayagam AV, Gratzer C, et al. A randomized, open-label, non-inferiority study of intravenous iron isomaltoside 1,000 (Monofer) compared with oral iron for treatment of anemia in IBD (PROCEED). Am J Gastroenterol. 2013 Dec;108(12):1877-88.

36 European Medicines Agency: Ema/579491/2013 new recommendations to manage risk of allergic reactions with intravenous iron-containing medicines, 2013, 2018,

37 Stein J, Hartmann F, Dignass AU. Diagnosis and management of iron deficiency anemia in patients with IBD. Nat Rev Gastroenterol Hepatol. 2010 Nov;7(11):599-610.

38 Kulnigg S, Teischinger L, Dejaco C, Waldhör T, Gasche C. Rapid recurrence of IBD-associated anemia and iron deficiency after intravenous iron sucrose and erythropoietin treatment. Am J Gastroenterol. 2009 Jun;104(6): 1460-7.

39 Carson JL, Grossman BJ, Kleinman S, Tinmouth AT, Marques MB, Fung MK, et al.; Clinical Transfusion Medicine Committee of the AABB. Red blood cell transfusion: a clinical practice guideline from the AABB*. Ann Intern Med. 2012 Jul;157(1):49-58.
40 Evstatiev R, Alexeeva O, Bokemeyer B, Chopey I, Felder M, Gudehus M, Iqbal T, Khalif I, Marteau P, Stein J, Gasche C; FERGI Study Group: Ferric carboxymaltose prevents recurrence of anemia in patients with inflammatory bowel disease. Clin Gastroenterol Hepatol. 2013 Mar;11(3):269-77.

41 Cúrdia Gonçalves T, Monteiro S, Barbosa M, Moreira MJ, Cotter J. P294 iron-deficiency without anemia in Crohn's disease: what are the predictive factors of recovery? J Crohns Colitis. 2017;11 suppl_1:S226.

42 Dan K. Thrombocytosis in iron deficiency anemia. Intern Med. 2005 Oct;44(10):1025-6.

43 Kulnigg-Dabsch S, Schmid W, Howaldt S, Stein J, Mickisch O, Waldhör T, et al. Iron deficiency generates secondary thrombocytosis and platelet activation in IBD: the randomized, controlled thromboVIT trial. Inflamm Bowel Dis. 2013 Jul;19(8):1609-16.

44 Simanek R, Vormittag R, Ay C, Alguel G, Dunkler D, Schwarzinger I, et al. High platelet count associated with venous thromboembolism in cancer patients: results from the $\mathrm{Vi}$ enna Cancer and Thrombosis Study (CATS). J Thromb Haemost. 2010 Jan;8(1):114-20.

45 Grainge MJ, West J, Card TR. Venous thromboembolism during active disease and remission in inflammatory bowel disease: a cohort study. Lancet. 2010 Feb;375(9715):657-63.
46 Jimenez K, Scharbert G, Leitner A, Schwabl P, Leiter F, Evstatiev R, et al. Pb534 iron deficiency increases platelet procoagulant capacity in a ferric chloride model of arterial thrombosis. ISTH; 2018.

47 Anthoni C, Russell J, Wood KC, Stokes KY, Vowinkel T, Kirchhofer D, et al. Tissue factor: a mediator of inflammatory cell recruitment, tissue injury, and thrombus formation in experimental colitis. J Exp Med. 2007 Jul;204(7): 1595-601.

48 Carter PR, Watts MN, Kosloski-Davidson M, Prasai K, Grisham MB, Harris NR. Iron status, anemia, and plasma erythropoietin levels in acute and chronic mouse models of colitis. Inflamm Bowel Dis. 2013 May;19(6):1260-5.

49 Ramakrishnan SK, Shah YM. Role of intestinal HIF-2alpha in health and disease. Annu Rev Physiol. 2016;78(1):301-25.

50 Jimenez K, Khare V, Evstatiev R, KulniggDabsch S, Jambrich M, Strobl H, et al. Increased expression of HIF2 $\alpha$ during iron deficiency-associated megakaryocytic differentiation. J Thromb Haemost. 2015 Jun;13(6): 1113-27. 